\title{
Formação complexa de conselheiro linguageiro: Experiência vinculada ao centro de autoacesso Base de Apoio à Aprendizagem Autônoma
}

Complex training of language learning advisor: Experience linked to the self-access center Support Base for Autonomous Learning

Formación compleja del orientador de idiomas: Experiencia vinculada al centro de autoacceso Base de apoyo para el aprendizaje autónomo

Recebido: 27/05/2021 | Revisado: 03/05/2021 | Aceito: 05/06/2021 | Publicado: 20/06/2021

Maria Clara Vianna Sá e Matos ORCID: https://orcid.org/0000-0002-3981-7232

Universidade Federal do Pará, Brasil

E-mail: matos_mariaclara@yahoo.com.br

Sônia Lumi Niwa

ORCID: https://orcid.org/0000-0001-6729-0784

Universidade Federal do Pará, Brasil

E-mail: sonialumi@gmail.com

Tiago da Fonseca Carneiro

ORCID: https://orcid.org/0000-0002-3427-4996

Universidade Federal do Pará, Brasil

E-mail: tiagofc@ufpa.br

\begin{abstract}
Resumo
O aconselhamento linguageiro é uma atividade ofertada em centros de autoacesso de universidades. Um dos seus papéis é apoiar o processo de aprendizagem de estudantes de línguas estrangeiras no que diz respeito à autonomia e à motivação. A pesquisa "Formação de conselheiro linguageiro com viés empreendedor e o processo motivacional de equipe de centro de autoacesso" tem entre seus objetivos propor caminhos para formar conselheiros linguageiros que possam atuar em centros de autoacesso, bem como em espaços no mercado de trabalho. Nesta pesquisa-ação, realizada sob a abordagem da complexidade, investiga-se como esse fenômeno se desenrola. Alguns do resultados parciais obtidos mostram que: (i) os passos se dão de modo interligado: aprende-se sobre a atividade de aconselhamento exercendo o papel de conselheiro em práticas guiadas com estudantes aconselhados, discutindo as atitudes tomadas e as leituras de apoio sobre o aconselhamento linguageiro, motivação e empreendedorismo; (ii) a configuração do grupo de pesquisa é a de uma dinâmica rede de apoio com conselheiros pesquisadores que apresentam competência linguística diversificada como usuários da língua estrangeira alvo e que frequentam ou já frequentaram o centro de autoacesso no qual este estudo está vinculado, sendo que alguns deles atuam na equipe como voluntários ou bolsistas voltados para gerenciar o espaço e as atividades nele ofertadas.
\end{abstract}

Palavras-chave: Aconselhamento linguageiro; Formação de conselheiro linguageiro; Motivação; Abordagem da complexidade.

\begin{abstract}
Language learning advising is an activity offered at university self-access centers. One of its roles is to support the learning process of foreign language students with regard to autonomy and motivation. The research "Formation of a language learning advising with an entrepreneurial bias and the motivational process of a self-access center team" has among its objectives to propose ways to form language learning advisors who can work in self-access centers, as well as in the job market. In this action research carried out under the complexity approach, we investigate how this phenomenon unfolds. Some of the results obtained show that: (i) the steps take place in an interconnected way: one learns about the language learning advising activity by exercising the role of advisor in guided practices with students who are advisees, by discussing the attitudes that are taken and the support readings on the theme of language learning advising, motivation and entrepreneurship; (ii) the configuration of the research group is that of a dynamic support network with advisors who are also researchers that present diverse linguistic competence as users of the target foreign language and who attend or have already attended the self-access center in which this study is linked by having participated in it its managing staff as a volunteers or as a scholarship holder who helps to organize the space and activities offered on it.
\end{abstract}

Keywords: Language counseling; Training of language learning advisors; Motivation; Complexity approach. 


\section{Resumen}

El asesoramiento lingüístico es una actividad que se ofrece en los centros universitarios de autoacceso. Uno de sus roles es apoyar el proceso de aprendizaje de los estudiantes de lenguas extranjeras en cuanto a autonomía y motivación. La investigación "Formación de un orientador de idiomas con enfoque emprendedor y el proceso motivacional de un equipo de centro de autoacceso" tiene entre sus objetivos proponer formas de calificar consejeros de idiomas que puedan trabajar en los centros de autoacceso, así como en el mercado laboral. En esta investigación-acción realizada bajo el enfoque de la complejidad, investigamos cómo se desarrolla este fenómeno. Algunos de los resultados parciales obtenidos muestran que: (i) los pasos se desarrollan de forma interconectada: se aprende sobre la actividad de asesoramiento ejerciendo el rol de consejero en las prácticas guiadas con los alumnos aconsejados, discutiendo las actitudes tomadas y las lecturas de apoyo sobre el asesoramiento lingüístico, motivación y espíritu empresarial; (ii) la configuración del grupo de investigación es de una red dinámica de apoyo con consejeros e investigadores que tienen diversa competencia lingüística como usuarios de la lengua extranjera de destino y que asisten o ya han asistido al centro de autoacceso en el que se involucra este estudio, y algunos de ellos trabajan en el equipo como voluntarios o becarios que manejan el espacio y las actividades que se ofrecen allí.

Palabras clave: Asesoramiento lingüístico; Formación de consejero de idiomas; Motivación; Enfoque de complejidad.

\section{Introdução}

Os centros de autoacesso que abordamos são aqueles voltados ao apoio da aprendizagem de línguas estrangeiras (LE) no que concerne principalmente ao desenvolvimento da autonomização de estudantes. Na Universidade Federal do Pará (UFPA), a Faculdade de Letras Estrangeiras Modernas (FALEM) conta com um espaço voltado para esse objetivo conhecido como Base de Apoio à Aprendizagem Autônoma $\left(\mathrm{BA}^{3}\right)$. Nesse laboratório ocorrem inúmeras atividades propostas por professores e estudantes vinculados à graduação em Letras com habilitação em Inglês, Francês, Espanhol, Alemão e em Língua Brasileira de Sinais (LIBRAS). Todas elas são de conhecimento do coordenador do espaço que, para gerenciá-las, conta com a atuação do $\mathrm{BA}^{3}$ Staff composto por bolsista(s), voluntário(s) e professor(es).

$\mathrm{O}$ aconselhamento linguageiro (AC) é uma das atividades oferecidas para fomentar aprendizagem no centro de autoacesso da FALEM. É uma modalidade de atendimento a estudantes com dificuldades, seja ela de ordem linguística, emocional ou afetiva, no processo de aprendizagem em uma língua estrangeira. Para fomentar maior eficiência nesse processo, em geral conta-se com a figura de um conselheiro linguageiro que se prepara para utilizar estratégias baseadas no diálogo, no contexto e em ferramentas articuladas a eles de modo que sirvam para apoiar de maneira personalizada o processo de aprendizagem de estudantes no papel de aconselhados (Mynard, 2012). Esse serviço é encontrado em centros de autoacesso de diversas partes do mundo. No Brasil, porém, ainda é pouco conhecido ${ }^{1}$. Desde 2011, a FALEM destaca-se como uma das poucas faculdades em universidades brasileiras que oferecem esse tipo de suporte. $\mathrm{O}$ alcance de bons resultados ${ }^{2}$ demonstra que o aconselhamento linguageiro tem potencial de influenciar e de transformar positivamente a trajetória de aprendizagem de conselheiros e de estudantes aconselhados.

Desde agosto de 2019, encontra-se em atividade na referida faculdade, o grupo de pesquisa "Formação de conselheiro linguageiro com viés empreendedor e o processo motivacional de equipe de centro de autoacesso" 3 do qual a primeira autora deste artigo é coordenadora e os outros dois autores encontram-se entre os professores pesquisadores participantes.

A justificativa para esse projeto baseia-se em duas constatações interligadas. A primeira, diz respeito à necessidade de avançar na compreensão do que seja aconselhamento linguageiro para praticá-lo com maior eficiência, bem como para formar novos conselheiros linguageiros que possam atuar na BA³ . Em geral, esses processos ocorrem vinculados à participação de pesquisadores nos projetos que abarcam a atividade de aconselhamento, como aqueles coordenados pela Professora Walkyria

\footnotetext{
${ }^{1}$ Para detalhes, ver Morhy (2015).

${ }^{2}$ Para conhecer mais a respeito da evolução dessa atividade ver o artigo "A relevância dos centros de autoacesso no processo da autonomia no aprendizado de línguas estrangeiras" (Aquino \& Schmidt, 2019), o livro "Centros de autoacesso e autonomia na aprendizagem de línguas estrangeiras: pesquisa e aprimoramento", (Rabelo \& Morhy, 2019) organizado e com capítulos escritos por colaboradores da BA³ dissertação de Mestrado (Morhy, 2015) e teses de doutorado (Dantas, 2019; Matos, 2019).

${ }^{3} \mathrm{Na}$ FALEM, UFPA.
} 
Magno e Silva de 2011 a 20194. Nesse contexto, em maio de 2017, no projeto "Processos de aconselhamento na aprendizagem de línguas, autonomia e motivação na perspectiva da complexidade", a referida pesquisadora, junto a outros cinco conselheiros já em serviço promoveram o primeiro curso de formação de conselheiros. Tal formação, com carga horária de oito horas, constou de três fases: (i) entrevista em grupo focal para selecionar, dentre os candidatos inscritos à formação, aqueles que apresentassem algumas das qualidades que um bom conselheiro deveria ter de forma a ser capaz de executar as ações referidas por Aoki (2012) ; (ii) discussão teórica, fase na qual foram lidos e discutidos diversos textos a respeito de aconselhamento linguageiro, autonomia, motivação para dar suporte teórico aos participantes e (iii) mãos à obra composta de uma fase de observação de sessões de aconselhamento dos conselheiros já em serviço, seguida de uma simulação de aconselhamento realizada em dupla entre os participantes da formação e os conselheiros já em atividade. O curso alcançou quatorze participantes, em sua maioria mulheres e estudantes de língua inglesa. Nesse sentido, ainda há necessidade de formar mais conselheiros pertencentes a outras licenciaturas ${ }^{5}$ para que mais alunos possam desfrutar dos benefícios do aconselhamento linguageiro. Vale a pena ressaltar outros dois aspectos relacionados à formação de conselheiros : (i) ao longo do período de 2011 a 2019 e também nesse primeiro curso, buscou-se contar com conselheiros que apresentassem boa competência linguística na língua alvo de aprendizagem do aconselhamento, característica que se alinha à ideia de que conselheiros são conhecedores dos instrumentos necessários para apoiar a trajetória de aprendizagem de aconselhados, bem como dominam a LE em foco (Mozzon-Macpherson, 2007) (ii) após o primeiro curso de formação, não houve sua reoferta e o número de conselheiros linguageiros atuantes na FALEM diminuiu, apesar da existência de demanda por esse serviço.

A segunda constatação envolve a necessidade de estimular e proteger a motivação dos integrantes do BA ${ }^{3}$ Staff, equipe que gerencia o centro de autoacesso da FALEM. Do ponto de vista do paradigma da complexidade, tudo e todos tecem relações entrelaçadas. Assim, para que os objetivos dessa equipe como o de ampliar a qualidade do atendimento das demandas do público frequentador desse centro de autoacesso possam ser alcançados, faz-se necessário não apenas lidar com a motivação dos estudantes e sim com a de todos os envolvidos no processo de aprendizagem alvo. Como os integrantes do BA ${ }^{3}$ Staff costumam ser majoritariamente graduandos, incentivá-los a interligar experiências de hoje como ponte para incrementar a carreira profissional de amanhã, tornando sua estada na universidade ainda mais produtiva e significativa, pode representar influência positiva para o processo motivacional dos mesmos. Por esse motivo, inserimos um viés empreendedor à atividade de aconselhamento.

Com esses ingredientes, o presente texto tem como objetivo mostrar alguns dos resultados que alcançamos com a interligação entre aprender e praticar aconselhamento linguageiro para também formar conselheiros linguageiros.

\section{Metodologia}

A investigação "Formação de Conselheiro Linguageiro com Viés Empreendedor e o Processo Motivacional de Equipe de Centro de Autoacesso" acontece em uma pesquisa-ação de cunho qualitativo sob preceitos do paradigma da complexidade.

Para Larsen-Freeman e Cameron (2008), adotar a abordagem complexa em investigações representa, entre outros movimentos, considerar a imprevisibilidade, a não linearidade, o dinamismo e a adaptação nas relações tecidas com o sistema complexo sob estudo, bem como perceber as transformações ocorridas. Com isso em mente, foram elaborados os seguintes objetivos específicos vinculados à proposta de um novo modelo de formação de conselheiro: (i) verificar como o grupo de

\footnotetext{
${ }^{4}$ Os projetos coordenados pela referida professora foram: “Aconselhamento linguageiro visando à motivação e à autonomia na aprendizagem de línguas estrangeiras" (2011-2013); "Aprendizagem de línguas estrangeiras como um sistema adaptativo complexo: autonomia, motivação e aconselhamento linguageiro" (2013-2015); "Processos de aconselhamento na aprendizagem de línguas, autonomia e motivação na perspectiva da complexidade" (2015-2017) e "Paradigma da complexidade na aprendizagem de línguas adicionais em espaços ampliados: autonomia, motivação e aconselhamento" (2017-2019).

${ }^{5}$ A FALEM também oferece cursos de licenciatura em língua francesa, espanhola e alemã.
} 
conselheiros pesquisadores enfrenta as circunstâncias impostas pelo dinamismo da evolução dessa formação no que concerne a adaptar ações, lidar com padrões de comportamento, bem como com inovações, estabelecendo pontes para outras agendas no aconselhamento; e (ii) acompanhar a atuação dos conselheiros pesquisadores e identificar momentos ou situações que perturbam positivamente ou não seu processo motivacional.

A opção pela abordagem complexa também é justificada pela prática do que Matos (2019) identifica como sendo aconselhamento complexo, cuja evolução na FALEM é descrita em 3.1. Uma vez que tudo se encontra interligado, isto também influencia a escolha pela pesquisa-ação para realizar nosso estudo acerca da formação de novos conselheiros. De acordo com Thiollent (2011, p.8), esta "pode ser concebida como método, isto quer dizer, um caminho ou um conjunto de procedimentos para interligar conhecimento e ação, ou extrair da ação novos conhecimentos". Para nós, ela foi concebida como oportunidade de gerar dados em situações de aconselhamento linguageiro que, enquanto fomenta estudos acerca dessa atividade, contribui para a formação de conselheiro. Com esse ponto de vista, concordamos com Matos (2019, p. 96) quando ela sugere que “cabe na definição acima, mudar o múltiplo 'ou', por 'e', quanto aos benefícios que pretendemos alcançar com essa estratégia de investigação".

Outros aspectos que nos interessaram da pesquisa-ação abordados por Thiollent (2011) encontram-se relacionados ao que Matos (2019, p. 96) também destaca, é “um diálogo e não um monólogo, como meio de identificação e resolução de problemas coletivos, com transformações advindas do aumento do conhecimento e da tomada de consciência no plano do agir", entrelaçadas “com as visões dos atores, o todo mutável no decorrer da ação” (Thiollent, 2011, p.10). Assim, identificamos nessa modalidade de pesquisa, características relacionadas a sistemas complexos como interações em diálogos, as transformações e as mutações que dizem respeito à emergência de problemas e de seus encaminhamentos. Para nosso estudo, foi primordial contar com a adaptabilidade ao contexto e a flexibilidade para lidar com ciclos de diagnósticos, reflexões e encaminhamentos geralmente atribuídos à pesquisa-ação. Em outras palavras, conforme Matos (2019, p.98) também aponta, isso nos leva “a assumir um desenho para a trajetória da nossa pesquisa” que não necessariamente inclui os círculos e espirais sugeridos para este método.

Por fim, outra característica da pesquisa-ação sugerida por Thiollent (2011, p.22) com impacto no nosso estudo diz respeito ao perfil dos participantes da investigação. Em relação a isso, Matos $(2019$, p. 98) ressalta do pensamento do referido autor

[...] é esperado que pesquisador e pessoas participantes sejam atores desempenhando 'um papel ativo na própria realidade dos fatos observados', tendo ampla e explícita interação na situação investigada, com voz e vez, sabendo o que dizer, o que perguntar e o que fazer.

Essa disposição para o diálogo, para a reflexão e para a ação é imprescindível aos componentes da nossa equipe, principalmente porque todos os membros do projeto da pesquisa são, a princípio, identificados como conselheiros linguageiros em formação que também são pesquisadores contribuindo para encaminhar os objetivos propostos em nossa investigação.

\subsection{Ambiente e quadro participativo}

De agosto de 2019 a março de 2020, os encontros para realizar nossa pesquisa ocorreram presencialmente na FALEM, no centro de autoacesso $\mathrm{BA}^{3}$. A partir do início da pandemia, a investigação é desenvolvida quinzenal ou mensalmente por meios virtuais.

No período anterior à pandemia, a composição da equipe de pesquisa abrangeu as seguintes características: 
(i) seis professores atuantes do quadro da UFPA, quatro de língua inglesa, dentre eles a coordenadora do projeto de pesquisa "Formação de conselheiro linguageiro com viés empreendedor e o processo motivacional de equipe de centro de autoacesso" e também coordenadora do centro de autoacesso $\mathrm{BA}^{3}$ na FALEM desde março de 2019, uma de língua francesa e um de língua alemã. Cinco desses professores acompanharam quase todos os projetos coordenados pela professora Walkyria Magno e Silva e almejam continuar sua formação de conselheiro linguageiro. Um dos professores de inglês que hoje possui vínculo temporário na instituição participou das pesquisas anteriores enquanto aconselhado durante o período da graduação.

(ii) três professoras de língua inglesa e uma de língua alemã não pertencem ao quadro da UFPA. Todas são ex-estudantes da FALEM, sendo que uma delas havia sido aconselhada quando foi estudante nessa faculdade;

(iii) dezessete estudantes graduandos da FALEM, oito de inglês, quatro de língua francesa, dois de língua espanhola e três de língua alemã. Desses, onze atuavam no BA ${ }^{3}$ Staff gerenciando o espaço e as atividades ofertadas. Dois deles participaram do último projeto de pesquisa coordenado pela professora Walkyria Magno e Silva acerca de aconselhamento linguageiro. Os demais participavam de grupo de pesquisa pela primeira vez iniciando sua formação em pesquisa.

(iv) A partir da pandemia, dez graduandos da FALEM deixaram o grupo de pesquisa, permanecendo apenas seis deles, sendo que destes apenas três atuavam como voluntários no BA ${ }^{3}$ Staff. Dois professores externos também deixaram de participar do grupo de pesquisa.

Além desses participantes, consideramos como membros eventuais da pesquisa estudantes que aconselhamos em grupo e individualmente. No período de agosto de 2019 a maio de 2021 aconselhamos em grupo oito estudantes e cinco deles individualmente. Antes de iniciar cada uma de suas participações todos eles têm tido a oportunidade de receber esclarecimentos acerca da pesquisa tanto por consultas individuais como por meio de visitas agendadas para conhecer nosso grupo antes de tomarem a decisão de colaborar ou não com o estudo. Depois desses esclarecimentos, disponibilizamos-lhes o termo de livre consentimento para oficializar suas participações.

\subsection{Procedimentos de pesquisa}

Para a geração de dados, temos utilizado os seguintes instrumentos: pautas e atas das reuniões, bem como relatórios individuais dos membros da pesquisa com informações que possam contribuir para o conhecimento (i) do andamento do aconselhamento com os estudantes individualmente e em grupo; (ii) de avanços no entendimento do que seja aconselhamento; e (iii) da formatação da formação de conselheiros linguageiros que implementamos.

Nesse percurso, para verificar os aspectos que apresentamos como resultados e discussão neste texto no que diz respeito à evolução do aconselhamento linguageiro na FALEM, foram considerados dados gerados no percurso das pesquisas acerca de aconselhamento realizadas na FALEM entre agosto de 2011 a maio de 2021. No que se refere à formação de conselheiro, consideramos dados gerados no ano de 2017, assim como aqueles obtidos entre agosto de 2019 a maio de 2021, compilados da nossa atual pesquisa "Formação de conselheiro linguageiro com viés empreendedor e o processo motivacional de equipe de centro de autoacesso". A análise dessas informações serve tanto para delinear uma melhor compreensão da prática de aconselhamento linguageiro, quanto para a configuração de um novo modelo de formação de conselheiro linguageiro. Em nossa pesquisa, frisamos novamente que não dissociamos esses fenômenos e isso influencia o modo como dispomos dos resultados e discussão que apresentamos a seguir. 


\section{Resultados e Discussão}

Nas próximas partes do texto esclarecemos a evolução da compreensão e da prática de aconselhamento linguageiro atrelada ao desenvolvimento da formação de conselheiro linguageiro que expomos a seguir.

\subsection{A evolução do entendimento e da prática no aconselhamento linguageiro na $\mathbf{B A}^{3}$}

De acordo com o que foi introduzido anteriormente, posicionamos aconselhamento linguageiro como uma modalidade de acompanhamento de aprendizagem de alunos de línguas estrangeiras (LE), visando incrementar o seu aprender a aprender, a sua reflexão e a tomada de atitudes decorrentes dessa reflexão. Segundo Mozzon-Mcpherson (2012; 2017), Kato e Mynard (2016), o aconselhamento linguageiro é mediado pelo diálogo entre as partes envolvidas: o conselheiro e o aconselhado.

O conselheiro é um agente sabedor de atitudes fundamentais ao aconselhamento (Matos; Morhy, 2016; Matos; 2019). Ele é uma figura que se prepara para saber proceder de forma que haja bem-estar na discussão acerca de questões relacionadas ao processo de aprendizagem. Para tanto, de acordo com Aoki (2012), há um conjunto de ações que pode ser utilizada pelo conselheiro: (i) buscar harmonia e empatia no relacionamento com o aconselhado; (ii) encorajar pensamentos e atitudes positivas em relação à LE que se aprende; (iii) abster-se de julgamentos e de atribuir conceitos avaliativos, o que pode contribuir para mitigar ansiedade no diálogo de aconselhamento; (iii) estar disponível para ouvir; (iv) ter habilidades de observar e de interpretar antes de se pronunciar; (v) dominar técnicas, como o espelhamento, a paráfrase e a sumarização (Stickler, 2001), para demonstrar que acompanha e se importa com o que diz o aconselhado; (vi) ajudar o aluno a descobrir seus reais problemas de aprendizagem (Kato \& Mynard, 2016); (vii) sugerir leques de alternativas para o aconselhado adotar e levá-lo a incluir suas próprias sugestões para experimentar; (viii) estar atento para fatores que favorecem e desfavorecem a aprendizagem; (ix) ajudar o aluno a reconhecer seus sucessos e aprender com seus desafios; (x) bem como dispor do conhecimento de uma grande quantidade de estratégias de aprendizagem (Oxford, 1990; Rabelo, 2016).

Já o aconselhado é um agente que, entre outros afazeres, estuda uma LE e deseja discutir algo relacionado a ela (Kato \& Mynard, 2016). Segundo aponta o estudo de Matos (2019), é comum um estudante procurar o aconselhamento linguageiro em busca de melhorar sua competência linguística, o que inclui, por exemplo, o desejo de aumentar o seu vocabulário e de aprimorar sua capacidade de entender o que um professor diz na LE em estudo. Porém, ele também o procura para compartilhar questões afetivas, que envolvem desmotivação e insatisfação com os resultados de seus estudos, bem como para aprender como pode se organizar melhor para estudar. Desse modo, nem sempre quem busca aconselhamento é o aluno menos proficiente.

No encerramento de um processo de aconselhamento, espera-se ter apoiado experiências transformadoras que mudem a natureza da aprendizagem do aconselhado, indo além de melhorias na sua proficiência linguística (Kato \& Mynard, 2016). Sob este prisma, segundo essas autoras, ao final de uma trajetória de aconselhamento, é desejável que o aluno consiga realizar autoaconselhamento, quando ele mesmo já consegue lidar com a sua aprendizagem, sendo capaz de refletir profundamente sobre ela e de explorá-la de modo produtivo.

Na referida faculdade, desde 2011, os estudantes costumam tomar conhecimento da atividade de aconselhamento em visitas programadas de conselheiros, aconselhados e ex-aconselhados às salas de aula; em seminários da UFPA e de outras comunidades acadêmicas; bem como pela circulação de informações entre eles que percebem que alguns de seus colegas encontram-se em processo de aconselhamento. Já os professores têm oportunidades de saber desse serviço da BA³ por meio das reuniões do Conselho da FALEM ${ }^{6}$ e em seminários de pesquisas em andamento. Assim, o estudante de LE pode tomar a iniciativa para buscar o serviço de aconselhamento ou pode ser indicado por um professor para experimentá-lo. $\mathrm{O}$ aconselhamento linguageiro oferecido geralmente ocorre individualmente e em grupo, presencialmente em diversos ambientes da faculdade e

\footnotetext{
${ }^{6}$ Instância administrativa que reúne todos os professores das diferentes licenciaturas ofertadas na FALEM.
} 
também de modo virtual (Morhy, 2015). Segundo Rabelo e Morhy (2019, p. 23), a “[...] flexibilidade, em termos de horário, local e necessidade individual, é um privilégio do aconselhamento" e esses aspectos têm sido mantidos entre conselheiros e aconselhados na nossa faculdade. Mais recentemente, devido à pandemia de covid-19, essa atividade desenvolve-se apenas online e a equipe de pesquisa coordenada pela professora Maria Clara Matos e o BA ${ }^{3}$ staff têm desenvolvido ações para chamar atenção da comunidade de que o aconselhamento linguageiro continua disponível aos estudantes.

De 2011 a 2019, temos observado que o perfil de estudantes aconselhados engloba graduandos de LE da FALEM e estudantes dos Cursos Livres de Línguas Estrangeiras, projeto de extensão também oferecido por essa faculdade.

A partir de 2013, com a adoção da abordagem da complexidade pela equipe de pesquisa da professora Walkyria Magno e Silva, o aconselhamento linguageiro implementado na FALEM inclui novos focos de investigação visando o seu aprimoramento. E o que se pretende com o olhar complexo?

Kramsch (2012), Paiva (2016), e Matos (2019) observam que a partir da primeira década do ano 2000 os estudos de Larsen-Freeman (1997) e de Larsen-Freeman e Cameron (2008) impulsionam o elo entre cientistas que aceitam o desafio de discutir a aprendizagem de LE sob um novo paradigma. Sabe-se que o interesse da Linguística Aplicada pelo paradigma complexo emerge por abranger, por exemplo, alternativas a modelos tradicionais, que medem as aprendizagens linearmente, do desconhecimento à proficiência similar à de um nativo, privilegiando visões dicotômicas para elucidar questões de sala de aula (Kramsch, 2012).A perspectiva complexa, ao adotar uma maneira holística para abordar a aprendizagem, considerando percepções do passado, a visão ideológica sobre a própria língua e seus falantes, bem como a interação com os diversos elementos de sua trajetória de aprendizagem (Kramsch, 2012) representa uma alternativa à visão compartimentalizada de ver a aprendizagem e o aprendente. Nessa perspectiva, não se isolam os componentes do fenômeno sob estudo, ao contrário, privilegia o seu comportamento em interação com os outros, aspecto mais afinado a como se apresentam na realidade. Dessa forma, podese reconhecer que aquilo que os estudantes de línguas aprendem não é produto de apenas um fator ou agente, mas da interação de uma infinidade de fatores. Entendemos que essa atitude de considerar atributos pessoais e contextuais interligados a trajetórias de aprendizagem como partes de um dinâmico sistema complexo (Mercer, 2015) é uma das principais implicações do paradigma da complexidade à nossa área de estudo. Apresentamos a seguir quais seriam outras voltadas para a prática do aconselhamento linguageiro.

Conforme já foi colocado em nota na introdução deste texto, desde 2011, o aconselhamento linguageiro praticado na FALEM foi se desenvolvendo por meio de projetos de pesquisa coordenados por Magno e Silva. A partir de 2013, quando se iniciou o projeto "Aprendizagem de línguas estrangeiras como um sistema adaptativo complexo: autonomia, motivação e aconselhamento linguageiro", relaciona-se a literatura estudada e as atitudes tomadas às premissas baseadas no paradigma da complexidade, verificando os impactos para o aconselhamento linguageiro entendido como um sistema complexo. Além da adoção do olhar holístico já mencionada, há várias outras repercussões dessa empreitada. Por exemplo, sob o ponto de vista da complexidade, o aconselhamento é uma atividade dinâmica, em constante mudança. É um processo e não um produto, o que resulta em uma trajetória em desenvolvimento para se explorar. É compreendido como uma atividade sujeita a interações com diversas pessoas envolvidas com o processo de aprendizagem de línguas estrangeiras, bem como com os diversos processos e fenômenos que acontecem concomitantemente ao aconselhamento que metaforicamente, não é uma ilha isolada, e sim uma vila na qual pessoas de diversas casas interagem e influenciam diversos aspectos da sua aprendizagem (Matos, 2019). Com isso é preciso considerar um aglomerado de fatores em movimento para planejar e implementar ações visando favorecê-la.

Além de processual, o aconselhamento identificado como sendo complexo (Matos, 2019) é não linear, com trajetória nem sempre progressiva. Segue o que é natural em qualquer circunstância de aprendizagem, sem garantias de qual será o seu desfecho. Esta realidade é contemplada quando entendemos que as possíveis transformações no aconselhamento pressupõem flexibilidade para caminhar em todas as direções e, que como um processo não-linear, as mudanças e transformações ocorridas 
são imprevisíveis (Kato \& Mynard, 2016). Ainda assim, as mesmas autoras elaboram perspectivas para o desenvolvimento do aconselhamento. Por exemplo, que, ao longo do aconselhamento, o conselheiro pode mudar o modo como o estudante vê o ensino e a aprendizagem de uma LE; que a relação com o aconselhado pode igualmente ser afetada por transformações, sendo comum conselheiros e aconselhados, ao final do aconselhamento, tornarem-se amigos e manterem contato, bem como o conselheiro transformar-se em um mentor ou em uma referência, acessível ao ex-aconselhado. Ademais, como já mencionamos, para o encerramento do aconselhamento, elas esperam que o aluno seja capaz de realizar autoaconselhamento. Porém, a realidade, pela abordagem complexa aponta que é incerto como isso se dá e se de fato se dará.

Identificar padrões de comportamento ao longo do aconselhamento, apesar da sua constante mobilidade e da singularidade de cada trajetória de aconselhamento, também faz parte do trabalho realizado sob as lentes da complexidade. Padrões de comportamento, favoráveis ou não à aprendizagem, equilibram uma trajetória por um determinado período de tempo. Eles são conhecidos como momentos de estabilidade dinâmica que criam oportunidades para a formação de atratores que, diante da emergência de algum gatilho, podem se desfazer, levando o sistema a ficar instável novamente, assumindo outras formas e garantindo a continuidade de seu desenvolvimento (Larsen-Freeman \& Cameron, 2008). O mapeamento dos motivos que fazem um aluno buscar um conselheiro para ajudá-lo não têm grandes variações (Kato \& Mynard, 2016). Percebe-se que são comuns os momentos em que o aconselhado se coloca passivo diante do seu processo de aprendizagem, bem como quando tem pouca clareza do que é estudar uma língua estrangeira, inclusive do quanto é importante exercitar a sua autonomia e saber lidar com a sua motivação para aumentar suas chances de sucesso. Reconhecer padrões dessa natureza vem contribuindo para a formulação de estratégias para enfrentá-los, propiciando mais dinamismo na trajetória de aconselhamento.

Outra questão a considerar é que a dimensão social no aconselhamento também aninha complexidade, pois considera que sistemas complexos encontram-se conectados a outros sistemas e subsistemas todos abertos a múltiplas influências com inseparáveis contextos, processos, fenômenos, agentes e elementos, no caso, interligados à atividade de aconselhamento linguageiro. Assim, ao mesmo tempo em que há um diálogo de um para um, podemos conceber diálogo também entre todas as partes ligadas ao aconselhamento. Essas interações afetam o modo como lidamos com a autonomia e a motivação nesse processo, que por sua vez inclui olhares para outros fenômenos como, por exemplo, para as emoções na aprendizagem e o seu papel de propiciar e constranger ação voltada à aprendizagem de uma LE (Kato \& Mynard, 2016; Oxford, 2016; Tassinari, 2016).

Por fim, é importante frisar que adotar o olhar da complexidade implica não atribuir exclusivamente ao aconselhamento linguageiro, os progressos na aprendizagem de LE. Além da concepção em uma vila (Matos, 2019) favorecer esse entendimento, Reinders (2008) reforça essa ideia ao mencionar que, concomitantemente ao aconselhamento, o aconselhado desenvolve outras ações, participando de aulas, de oficinas e de outras atividades que também contribuem para o desenvolvimento da LE que aprende.

\subsection{Caminhos para uma nova formação de conselheiro linguageiro}

Conforme colocamos anteriormente, um dos focos da nossa pesquisa é propor um modelo alternativo de formação de conselheiro linguageiro. Aqui expomos quais foram os encaminhamentos a este respeito.

Como adotamos uma concepção complexa de aconselhamento linguageiro e um modelo de pesquisa compatível com esse olhar, a configuração de formação que se instaurou também se alinha à mesma abordagem, originando a denominação de formação complexa de conselheiro linguageiro, título deste texto. Um desdobramento dessas escolhas diz respeito aos temas centrais da investigação: compreensão de aconselhamento linguageiro; formação de conselheiro linguageiro; percepção da motivação e viés empreendedor a serem explorados de maneira interligada. Ter em vista suas interligações fomenta o modus operandi da formação de conselheiro que implementamos. Com isso outros direcionamentos ganharam forma, como: 
(i) A emergência de aconselhamento no grupo de pesquisa como parte da formação de conselheiro. Considerando que, na perspectiva da complexidade, o contexto é indissociável da compreensão do fenômeno em estudo, além da leitura e da discussão de textos no grupo de pesquisa, nós, pesquisadores, estamos atentos ao que acontece nos ambientes interligados à pesquisa, como a BA³ , as salas da graduação e dos Cursos Livres de Línguas Estrangeiras, observando também as circunstâncias dinâmicas atreladas a eles, como momentos de provas, bem como outras preocupações e alegrias de estudantes e professoras. Com base em percepções dessa natureza, ações foram elaboradas visando incluí-las de modo a favorecer a evolução da formação de conselheiro no lugar de paralisá-la. Tornar este comportamento mais consciente tem sido um exercício constante. Dele resultou a nossa iniciativa de convidar para conhecer nosso grupo de pesquisa, uma aluna dos Cursos Livres de Línguas Estrangeiras que buscava informações acerca do aconselhamento na BA ${ }^{3}$ no momento de uma das nossas reuniões. Além de nos contar que há mais de um semestre desejava ser aconselhada e não conseguia se encaixar na agenda disponibilizada por conselheiros atuantes na FALEM, ela compartilhou conosco suas aflições voltadas à aprendizagem de inglês. Por meio das perguntas e das sugestões que lhe fizemos, percebemos que essa conversa se configurou em um momento de aconselhamento linguageiro em grupo. Como a estudante manifestou interesse em continuar sendo aconselhada nessas circunstâncias, enviamos-lhe um termo de livre consentimento para que o apreciasse e disponibilizamos-nos para esclarecer dúvidas para que pudesse decidir sobre assiná-lo ou não. Para que um aluno(a) venha a se tornar um(a) aconselhado(a) integrado(a) à nossa investigação, faz-se necessário a assinatura de tal documento. Entendemos que esses procedimentos se alinham a aspectos éticos, principalmente o relacionado à transparência dos objetivos e dos passos da investigação. A experiência com essa aluna passou a ser denominada de prática guiada de aconselhamento linguageiro. Entre 2019 e 2021, oito estudantes iniciaram seu aconselhamento dessa maneira (cinco de língua inglesa e duas de língua francesa. Pelas lentes da complexidade, este foi um momento de adaptação e de inovação como uma maneira de lidar com fatores contextuais no lugar de excluí-los, um modo de utilizar recursos que percebemos como disponíveis. Para nós, isso representou o início de um outro caminho para aconselhar e para formar conselheiros linguageiros.

(ii) A abertura para múltiplas aprendizagens dos participantes. Depois da primeira experiência de aconselhamento na reunião do grupo de pesquisa, recebemos outros estudantes que desejaram tornar -se aconselhados. Estes, tomam conhecimento da atividade de aconselhamento linguageiro como um serviço da BA ${ }^{3}$ por meio de ações que têm partido dos pesquisadores. Quando escolhem aceitar nosso convite para estar presente nas reuniões, têm oportunidade de conhecer mais acerca da atividade de aconselhamento e do funcionamento da investigação, tendo acesso aos momentos de estudo de conselheiros, bem como ao registro de dados para alcançar os objetivos da pesquisa. Assim, o estudante conhece como é participar de um projeto de pesquisa, e, na medida em que ele é exposto aos momentos de discussão nas nossas reuniões, tem voz para colocar como percebe o aconselhamento linguageiro, as atitudes de conselheiros e tem espaço para aprender também como se tornar um conselheiro, expandindo o potencial de ganhos com a participação na nossa investigação. Essas possibilidades têm forte ligação com o método da pesquisa-ação - com todos de algum modo assumindo um papel ativo também como investigadores que contribuem para elucidar questões em comum.

(iii) A adoção da não linearidade na formação de conselheiros linguageiros. O projeto da nossa pesquisa buscou favorecer a participação de professores e estudantes de todos os cursos da $\mathrm{FALEM}^{7}$, sendo que estes poderiam integrar o grupo em diferentes estágios de competência linguística ${ }^{8}$. Este aspecto também foi inovador, pois a condução do aconselhamento linguageiro atrelado a grupos de pesquisa e o curso de formação de conselheiros linguageiros oferecidos anteriormente na FALEM envolveram, na maioria das vezes, estudantes mais experientes nas línguas que estudavam. Vemos que esse outro formato encontra ligação com

\footnotetext{
${ }^{7}$ Cursos de licenciatura em alemão,espanhol, francês, inglês e LIBRAS.

${ }^{8}$ Ver composição do quadro participativo dessa pesquisa em 2.1 .
} 
entendimento de hierarquia sob o olhar complexo. Trabalha-se então, com uma dinâmica rede de apoio (Capra \& Luisi, 2015) que se distingue da figura de uma pirâmide com níveis de participação estanques e com claras distinções (Mariotti, 2010).

Para a formação de conselheiro, manter em mente a concepção de rede mostrou-se compatível com o entendimento de que os estudantes, visitantes nos encontros de pesquisa, são aconselhados do grupo, ou seja, de todos os conselheiros em formação e não apenas de um membro específico da pesquisa, mais experiente como usuário de uma LE, alvo de aprendizagem. Isso está sendo possível uma vez que notamos que, de algum modo, os conselheiros, nessas circunstâncias, podem ajudar no processo de aprendizagem em geral, seja sugerindo estratégias de aprendizagem, de organização de estudo ou disponibilizandose para escutar o que aconselhados sentem ao aprender, seja atuando para perturbar comportamento, ideias, atitudes que não favorecem a aprendizagem da língua alvo. É uma maneira também de multiplicar ações de aconselhamento com diferentes gradações da oferta desse serviço. Para tanto, não se exclui a possibilidade do apoio de um único conselheiro com boa competência na LE alvo de estudo, assim como se inclui a atuação daqueles que, participando dos momentos de formação, preparam-se para praticar aconselhamento independentemente da LE em que são linguisticamente competentes, contribuindo para encaminhar algum desafio da trajetória de aprendizagem de aconselhados.

Um outro desdobramento dessa hierarquia complexa, diz respeito a conselheiros em formação que são também aconselhados, situação proporcionada pela abertura para o dinamismo das participações. Como ilustração disso, citamos que no decorrer da pesquisa, três conselheiras em formação ${ }^{9}$ interessaram-se em também ser aconselhadas, exercendo duplo papel durante a formação de conselheiro proposta na pesquisa. Uma delas experimentou o que denominamos de aconselhamento avulso. Nesse caso, ela almejou preparar-se para a defesa de seu trabalho de conclusão de curso, objetivo que alcançou durante um curto espaço de tempo, em poucos encontros com um mesmo conselheiro fora dos momentos de reunião. As outras, buscavam apoio mais personalizado para desenvolver com maior eficiência seus respectivos cursos de graduação e, individualmente, procuraram ajuda mais duradoura de outros conselheiros em formação, também participantes da pesquisa.

(iv) O estudo de padrões de comportamento de aconselhados e conselheiros. Aqui, reiteramos a premissa de que, pelo viés complexo, é esperado estudar o dinamismo das situações, bem como os momentos de estabilidade dinâmica que são edificados por padrões de comportamento. Durante o aconselhamento em grupo, iniciou-se o mapeamento de situações relacionadas ao comportamento de aconselhados e de conselheiros. Em relação aos primeiros, observou-se a expressão de:(i) crenças desfavorecendo a aprendizagem como em: "Os alunos de Letras têm mais vantagens para aprender do que os nos Cursos Livres de Línguas Estrangeiras"; (ii) de emoções negativas como em: "Fui mal na prova de inglês novamente e vou desistir deste semestre de estudo. Volto depois"; e (iii) de lacunas a respeito da compreensão do que seja o estabelecimento de objetivos viáveis para aprender uma LE, como em: "Quero aprender inglês até o final do ano". Em relação aos segundos, mapeamos a expressão de dúvidas acerca do funcionamento do aconselhamento como por exemplo: (i) "Como explicar o que é aconselhamento linguageiro para aconselhados?”; (ii) “Como melhorar a divulgação do aconselhamento linguageiro e a recepção de documentos iniciais de aconselhamento?"; (iii) "Noções de empreendedorismo e de autoria e plágio na escrita e na oralidade caberiam em quais circunstâncias na agenda de aconselhamento?”.

Esses achados integram as histórias de aconselhamento que acompanhamos e da formação de conselheiros que propomos. As reflexões sobre como lidamos com essas situações e sobre como podemos enriquecer, adaptar e transformar os procedimentos que adotamos mediante mudanças contextuais sutis e mais evidentes constituem dados da pesquisa, logo, são também analisados quando das reuniões da equipe pesquisadora. O mapeamento das já referidas situações permite-nos verificar as recorrências o que nos levou a aprimorar a ideia de registrá-las em protocolos, como guias ajustáveis que possam servir como documento para futuras formações de conselheiros.

\footnotetext{
${ }^{9}$ Duas graduandas em língua alemã e uma de língua francesa.
} 
(v) A expansão da agenda de aconselhamento linguageiro. Faz parte da nossa jornada de pesquisa considerar o empreendedorismo e a motivação na prática de aconselhamento e no processo de formação de conselheiro linguístico que lhe interligamos. Para enredar esses temas, consideramos que o aconselhamento linguageiro engloba uma pauta centrada nas necessidades dos estudantes que inclui abordar a sua motivação para aprender. Um caminho para lidar com o processo motivacional de aconselhados tem sido vincular o uso da LE ao presente, mas também à construção de uma identidade para o futuro do estudante (Dörnyei \& Ushioda, 2011). Desde a elaboração do projeto da nossa pesquisa, pensamos em lidar também com a motivação dos conselheiros de formação visando, principalmente, alcançar os membros da pesquisa que integram o BA ${ }^{3}$ staff para que possam disponibilizar mais serviços de aconselhamento linguageiro no laboratório da FALEM e, possivelmente, inovar ao lançá-los no mercado de trabalho. Para desenvolver essa questão, vislumbramos um espaço para a introdução de noções de empreendedorismo, não só para aconselhados, mas para os conselheiros em formação. Diante de um mundo "[...] repleto de transformações sem precedentes e de incertezas tão radicais [...]" (Harari, 2018, p. 319), defendemos a ideia de que lidar com isso não pode ser adiado, em especial porque observamos que esse tema ainda não chegou às salas de aula da graduação. Ressaltese que a ausência dessa temática nos Projetos Pedagógicos da FALEM foi motivo de crítica por parte dos avaliadores do Ministério da Educação, quando da avaliação de um dos cursos da referida faculdade realizada em 2018. Até o presente momento, realizamos algumas leituras e discussões de textos básicos para compreender o que é empreender e percebemos como isso afeta a motivação dos estudantes e dos professores membros da pesquisa. Os primeiros sentiram-se instigados a conjecturar o seu lançamento no mercado de trabalho como conselheiro linguageiro. Os segundos vinculam esse novo conhecimento à perspectiva de conversar também sobre isso em sala de aula e com seus familiares para levá-los também a refletir sobre a necessidade de empreender nos dias de hoje. Ainda não nos sentimos preparados para avançar esse diálogo com nossos aconselhados.

\section{Considerações Finais}

A aprendizagem acerca do que seja e como realizar aconselhamento linguageiro desenvolve-se na FALEM desde 2011. Desde 2013 esse percurso vem sendo atrelado à abordagem complexa. Toda essa trajetória está vinculada à participação em grupos de pesquisa que elucidam esses temas e cujos integrantes realizam aconselhamento em momentos distintos como um serviço do centro de autoacesso BA ${ }^{3}$. Desde os primeiros momentos, a formação de conselheiros linguageiros acontece nesses grupos ao estudar aspectos teóricos da complexidade e considerá-los para o aconselhamento oferecido aos estudantes de LE. É também fruto dessa trajetória o curso de formação de conselheiro linguageiro realizado em 2017. Nessa, já voltávamos o olhar complexo ao aconselhamento, mas isto não predominou no desenho desse curso, ao menos não explicitamente. Esperamos contribuir para avançar nessa direção ao propor formação de conselheiros linguageiros alinhada a esse outro prisma como uma escolha coerente com a abordagem que adotamos e como uma maneira de compor o mosaico de estudos que fortalecem a sua consolidação para a geração de conhecimento científico.

Adotar o olhar complexo tem implicado explorar diferentes perfis dos participantes da formação de conselheiro e considerar a abertura de sistemas complexos e dinamismo contextual para conectar outros agentes visando favorecer o aconselhamento. Consideramos como impacto disso, a configuração de uma rede de apoio composta por questões de aconselhados e da formação de conselheiros que motivam variadas possibilidades de ações de aconselhamento. Em relação a essas características, proporcionamos formação de conselheiros para estudantes que cursam desde os semestres iniciais aos finais das licenciaturas da FALEM sem vinculá-la a um determinado nível de competência linguística desses agentes. Entendemos que, dessa forma, propiciamos a todos os alunos a possibilidade de potencializar a aprendizagem da língua alvo, assim como inserirse em um ambiente de pesquisa o que, certamente, contribuirá para a sua formação enquanto professor. Quanto aos professores participantes, alguns continuam sua formação, pois já tinham experiências prévias como conselheiro e outros começaram a sua 
formação ao ingressarem na nossa pesquisa. Eles também aconselham estudantes que aprendem uma língua que difere daquela em que são licenciados. Nessas circunstâncias, buscamos agregar suas histórias, enriquecer e adaptar estratégias para desafios que podem ser comuns à aprendizagem de qualquer LE. De acordo com nossos dados, isso vem repercutindo favoravelmente no andamento do aconselhamento ao proporcionar, sobretudo, maior bem-estar ao processo de aprender mediante a percepção de que o processo de aprendizagem não precisa ser solitário, que pode ser solidário mediante maior conscientização de pertencimento a uma rede de aprendizagem da qual o aconselhamento linguageiro participa e incentiva a expansão.

Em relação aos nossos maiores desafios, além de avançar na interligação entre aspectos motivacionais dos participantes considerando um viés empreendedor no aconselhamento linguageiro, precisamos focar nossos esforços para tornar sustentável o modelo de formação que propomos para a $\mathrm{BA}^{3}$ de modo que ele não estanque no momento final desta pesquisa, assim como para melhor descrever esse processo para que ele possa inspirar adaptações em outros centros de autoacesso, de forma a expandir a oferta do serviço de aconselhamento que, acreditamos, ser de grande valia para potencializar a aprendizagem de línguas. Um norte que temos para isso é manter em mente a relevância de grupos de estudo ou/e de pesquisa vinculados a estes espaços como apoio contínuo ao serviço de aconselhamento.

Além dessas questões, pretendemos explorar em futuros trabalhos temas relacionados ao desenvolvimento do bem-estar na aprendizagem de língua estrangeira em trajetórias tanto de aconselhamento linguageiro quanto de formação de futuros conselheiros linguageiros. Para tanto, poderá ser frutífero conhecer melhor se e como centros de autoacesso ao redor do mundo abordam esses assuntos para tornar suas atividades ainda mais acolhedoras.

\section{Referências}

Aoki, N. (2012). Can-do statements for advisors. In Ludwig, C. \& Mynard, J. (Org.). Autonomy in Language Learning: advising in action (pp. 154-163). Canterbury: IATEFL.

Dantas, L. (2019). O processo de autonomização à luz do paradigma da complexidade: Um estudo da trajetória de aprendizagem de graduandos em LetrasInglês. Tese de doutorado (Doutorado em Linguística) - Universidade Federal do Pará. Brasil. http://repositorio.ufpa.br/jspui/handle/2011/11219.

Capra, F. \& Luisi, P. (2015). A visão sistêmica da vida: Uma concepção unificada e suas implicações filosóficas, políticas, sociais e econômicas. São Paulo: Cultrix.

Dörnyei, Z. \& Ushioda, E. (2011). Teaching and researching motivation. Pearson.

Harari, Y. (2018). 21. Lições para o século 21. Companhia das Letras.

Kato, S. \& Mynard, J. (2016). Reflective Dialogue: advising in language learning. Routledge.

Kramsch, C. (2012). Why is everyone so excited about complexity theory in applied linguistics. Mélanges Crapel, 33, 10-24.

Larsen-Freeman, D. (1997). Chaos/complexity science and second language acquisition. Applied Linguistics, 18 (2), $41-165$.

Larsen-Freeman, D. \& Cameron, L. (2008). Complex systems and applied linguistics. Oxford University Press.

Mariotti, H. (2010). Pensamento complexo: suas aplicações à liderança, à aprendizagem e ao desenvolvimento sustentável. Atlas.

Matos, M. \& Morhy, S. (2016). Estados atratores em trajetórias de aconselhamento linguageiro na aprendizagem de línguas estrangeiras. In Silva, W. \& Borges, E. (Org.), Complexidade em ambientes de ensino e de aprendizagem de línguas adicionais. (pp. 199-222). CRV.

Matos, M. C. V. S. (2019). Contribuições do paradigma da complexidade no desenvolvimento de estratégias motivacionais empregadas no aconselhamento linguageiro. Tese de doutorado (Doutorado em Linguística) - Universidade Federal do Pará. Brasil. http://repositorio.ufpa.br/jspui/handle/2011/11566.

Mercer, S. (2013). Towards a complexity-informed pedagogy for language learning. Revista Brasileira de Linguística Aplicada, 13 (2), $375-398$.

Morhy, S. (2015). A influência do aconselhamento linguageiro na trajetória de uma aluna de Letras inglês. Dissertação (Mestrado em Linguística) Universidade Federal do Pará. Brasil. http://repositorio.ufpa.br/jspui/handle/2011/8033.

Morhy, S. \& Rabelo, J. (Org.). (2019). Centros de autoacesso e autonomia na aprendizagem de línguas estrangeiras: pesquisa e aprimoramento. Pontes.

Mozzon-McPherson, M. (2007). Supporting independent learning environments: An analysis of structures and roles of language learning advisers. System, 35 (1), 66-92. 
Research, Society and Development, v. 10, n. 7, e24910716554, 2021

(CC BY 4.0) | ISSN 2525-3409 | DOI: http://dx.doi.org/10.33448/rsd-v10i7.16554

Rabelo, J. (2016). Fomento da autonomia na aprendizagem de inglês por meio do aconselhamento linguageiro: Um estudo de caso sob a perspectiva ecológica. Dissertação (Mestrado em Linguística) - Universidade Federal do Pará. Brasil. http://repositorio.ufpa.br/jspui/handle/2011/8151.

Reinders, H. (2008). The what, why, and how of language advising. MexTESOL, 32 (2), 13-22.

Schmidt, C. \& Aquino, T. C. (2021). Die Relevanz der Selbstlernzentren für die Autonomiebildung beim Fremdsprachenlernen an der Universität. Pandaemonium Germanicum, 24 (42), 193-216.

Stickler, U. Using counselling skills for language advising. In Mozzon-McPherson, M. (Org.). Beyond language teaching towards language advising (pp. 4050). Londres: Central Books.

Tassinari, M. G. (2016). Emotions and feelings in language advising discourse. In Gkonou, C. et al. New directions in language learning psychology. (pp. 7196). Springer: Cham.

Thiollent, M. (2011). Metodologia da pesquisa-ação. Cortez. 